\title{
EVALUATION AND COMPARISON OF THE ENGLISH TEXTBOOKS OF UPPER PRIMARY SCHOOLS OF WESTERN REGION OF INDIA IN THE LIGHT OF NCF
}

\author{
Prof. Dr. Jagdish S Joshi \\ Dr. Jaydip K. Savaliya
}

\begin{abstract}
It is believed that the textbook is a significant medium in the present education system. Textbook is one of the proven authoritative sources to establish values in students in the elementary stage. Students are mostly depended on the textbook at this stage. So it is necessary, the textbook should be a complete package which develops students' life in all strata of life. NCERT developed NCF in 1975 following the recommendation of Education Policy on 1968. NCERT develops National Curriculum Framework which provides guidelines for developing textbooks and school curriculum. NCF-2005 prepared by NCERT discusses a wide range of issues related school education. So evaluate the textbooks of English of upper primary schools of western region of India in the light of NCF 2005. Textbooks are in the regional mediums. Textbooks of English are assessed with the reference of NCF-2005. English textbooks have almost all the qualities or as per the NCF2005's suggestion except one parameters. Out of all the textbooks of five states, there is no any activity which is based on "Peace'. Authors found that said textbooks are decent and team of textbook preparation work properly to follow NCF. All the states are followed NCF above $87 \%$. It is a good score.
\end{abstract}

Key Words: Evaluation, Comparison, Upper primary schools, Western region of India, NCF-2005, English textbook

\section{Introduction}

Education plays a vital role in the development of a nation. It is believed that the textbook is a significant medium in the present education system. Textbook is one of the proven authoritative sources to establish values in students in the elementary stage. Students are mostly depended on the textbook at this stage. So it is necessary, the textbook should be a complete package which develops students' life in all strata of life. A textbook is one of the powerful medium for the overall development of students. Textbooks have been identified for most instructional tool in any subject of the study. Students can be used it for learning in the school or at home. Textbook arouses the attention of the pupils and gives comprehensive and enlarged learning experiences. NCERT published first National 
Curriculum Framework in 1975 to prepare curriculum and textbooks. One of the main objective of NCF 2005 is overall development of children. NCF 2005 is significant for prepares textbooks so evaluate textbooks of English of upper primary (standard six, seven and eight) of regional medium of western region of India in the light of NCF 2005.

\section{National Curriculum Framework}

Indian constitution permitted the state government to take decisions regarding to school education incorporating curriculum till 1967. The centre could only facilitate direction to the state on policy subjects. Early effort of National Education policy of 1968 the Curriculum Framework designed by NCERT in 1975 were formulated. NCERT prepared NCF in 1975 subsequent the recommendations of Education Policy on 1968. The country as a whole had a National Policy on Education which imagine National Curriculum Framework as a means of modernising education. NCERT was given the duty of developing the National Curriculum Framework and reviewing the framework at regular times. The first NCF came in 1975 and last in 2005. NCERT develops National Curriculum Framework which offers plans or strategies for developing textbooks and school curriculum. NCF-2005 equipped by NCERT to deliberates an extensive assortment of issues regarding school education.

\section{Evaluation of Textbook}

Authors selected textbooks of English of standard six, seven and eight of regional medium of western region of India (Gujarat, Rajasthan, Madhya Pradesh, Maharashtra and Goa) for the present paper. Whole textbooks are evaluated in the light of the NCF-2005. Authors decide parameters from NCF-2005 for evaluation.

\section{- Connecting knowledge to life outside the school}

Lesson No: 2, Activity No: 6: Read sentences and find out which day is indicated (Gujarat, English VI: First sem., SL 25).

Lesson No: 3, Activity No: 8: Project (Gujarat, English VII: First sem., SL 33).

Students are instructed to fill up the table with the help of their collected rappers. Students take the help of science teacher and discuss the ingredients. They are harmful or harm less.

Lesson No: 5, Activity No: 1: Play the game (Gujarat, English VII: Second sem. SL 54). It asks the students to play the 'Fixed answer' and 'Where is my answer' game. Teacher also helps the students to play this game. First of all teacher fixed any one answer by the students after that teacher asks any question to them. Students will give the fixed answer. Lesson No: 1, Activity No: 6B: Plan a quiz for school (Gujarat, English VIII: First sem., SL 11).

It asks the students to prepare questions for quiz. Students watch any quiz programme on TV. They listen carefully the instruction for the different round of the quiz at last organize a quiz in the class room.

Lesson No: 11, Activity No: L: Road safety (Rajasthan, English VI, SL 75).

Present activity is about road safety. Some rules of road safety are given. Rules aware students about driving and their safety. 
Lesson No: 4, Activity No: 4: Visit public place (Rajasthan, English VII, SL 24).

It asks the students to visit public place like school/ bus stand, etc. Students are asked the question they are dirty or not. If they are dirty then find out the reasons and speak in the class. Students also give advice or discuss what they can do to keep the public places clean.

Lesson No: 3, Activity No: 5: What a black smith does? (Rajasthan, English VIII, SL 20). Students are instructed to find out what a black smith does? How is Black smith useful to the society? Students write their experiences in the short paragraph.

Lesson No: 3, Activity No: 7: Find out useful and harmful insects (M.P., English VI, SL 15). Students are instructed that there are many insects exist around them. Some are useful and some are harmful. Write the name of at least two useful and harmful insects. Students also draw the picture of those insects.

Lesson No: 5, Activity No: 7B: Fill up railway reservation forms (M.P., English VII, SL 33).

It asks the students to get a railway reservation form from the railway reservation window and fill it.

Lesson No: 12, Activity No: 8: Visit any tribal village and collect their information (M.P., English VIII, SL 113).

It asks the students to visit any tribal village or talk with the teacher and collect more information about different tribes of Madhya Pradesh.

Lesson No: 2, Activity No: 2.6.4: Find out how paper and plastic are recycled (Maharashtra, English VI, SL 46).

It asks the students to find out how paper and plastic recycle. Students work on their own self and complete this activity.

Lesson No: 2, Activity No: 1.5: Write a conversation between two brother (Maharashtra, English VII, SL 46).

Students are instructed to write a conversation between two brother or two sisters or brother and sister. One condition is given to the students that younger is learning to swim or ride a bicycle. Students prepare a conversation.

Lesson No: 2, Activity No: 13B: Prepare short news item (Maharashtra, English VIII, SL 86).

It asks the students to prepare a short news item on any event of their choice. They are suggested that also prepare a headline along with news item.

Lesson No: 8, Activity No: 5.2: Find out the different kinds of work done by the people in neighbourhood (Goa, English VI, SL 94).

It asks the students to search out which types of job done by the people in their neighbour. Students make different cards for the different types of work. It is also instructed to use the pictures and make the card colourful.

Lesson No: 5, Activity No: 3.4: Speak to five adult in your neighbourhood. Ask them questions (Goa, English VII, SL 81).

Students are instructed to communicate with the adult who live near to them. Some questions are given here, ask these questions to them. Students share their findings with the class. These questions are related with the use of plastic packet, from where to purchase?, about footwear and cloth.

There is no any activity related to this point in standard eight. 


\section{- Learning is shifted away from rote method}

Rote learning is a memorization technique base on repetition. The idea is that one will be able to quickly recall the meaning of material the more one repeats it. NCF-2005 decides to shift learning from rote method.

There is no any activity related to rote method in Gujarat, Rajasthan, Madhya Pradesh and Goa

There is no any activity related to rote method in standard six and eight.

Textbooks of English of standard seven of Maharashtra have some activity on repetition. Lesson No: 1, Activity No: 8.1A: Look, remember and write (English VII, SL 19).

Students are instructed to read the words carefully for two minute. They close the book, write down maximum pairs. They can write within three minutes. Students compere their list with the words given there.

Lesson No: 2, Activity No: 5.6.1A: Write words (English VII, SL 4).

It asks the students to look at words carefully for two minutes. They close the book, write maximum words within three minute.

\section{- Overall development of children}

Lesson No: 1, Activity No: 4: Prepare attendance register (Gujarat, English VI: First sem., SL 5).

Students are instructed to work in group, prepare an attendance register of group members of last one week and make sentences on the bases of register.

Lesson No: 3, Activity No: 4: Play the game 'I Say' (Gujarat, English VII: First sem., SL 28). Students are played the game by the teacher. After the game, students read different circumstances which are given and what is students' reaction for the particular circumstances? Students choose the proper reaction from the bracket.

Lesson No: 4, Activity No: 6A: Play the game (Gujarat, English VIII: First sem., SL 36).

It asks the students to play the game 'Have you been unique?' with the help of their teacher. Teacher asks the different questions in the class and students give the answer. If only one student gives the answer, he is a unique.

Lesson No: 3, Activity No: 5A: Find out how electricity and water are used (Rajasthan, English VI, SL 23).

It asks the students to look around the nearby area of their house. They find out how electricity and water are used and how waste is disposed. After completed this task students write a short paragraph on it.

Lesson No: 5, Activity No: L: Conversation between students and honour of canteen (Rajasthan, English VII, SL 26).

It asks the students to study the conversation between student and canteen honour. It says that read and learn how to speak in similar situation.

Lesson No: 4, Activity No: 5: Draw the different types of trees (Rajasthan, English VIII, SL 26). 
It asks the students to draw different types of trees found in their area. Students are instructed to give the name of the trees which are drawn by the students.

Lesson No: 7, Activity No: 5: Work with partner and collect the information which game he/ she plays (M.P., English VI, SL 40).

It asks the students to work with the partner. Students ask the given questions to their partner and collect the information about which game he/she plays.

Lesson No: 11, Activity No: 5: Discuss about festivals and complete the table (M.P., English VII, SL 85).

Students are instructed to discuss about different festival such as Diwali, Id, and Christmas. Students collect information about these festival and complete the table. There are five columns- Name of festival, when it is celebrated, how it is celebrated, why it is celebrated etc. Students discuss any three festivals and collect information which are suggested in the table and complete it.

Lesson No: 7, Activity No: 8: Make a 'First Aid Kit' (M.P., English VIII, SL 84).

It asks the students to prepare a 'First Aid Kit' for their school or class. Students can take help of their teacher or friends to prepare it. List of things are given. There are some basic need at the time of injury, they are given in the list.

Lesson No: 4, Activity No: 4.3.6: Form a pair and make a list of ten everyday problems and their solutions (Maharashtra, English VI, SL 91).

Students are instructed to form a pair and make a list of problems from their day to day life and also suggest their solutions.

Lesson No: 3, Activity No: 3.3: Make an attractive booklet (Maharashtra, English VII, SL 91).

It asks the students to make an attractive booklet for translations of their favourite proverbs, good thought and poem.

Lesson No: 3, Activity No: 9F: Use your imagination and write (Maharashtra, English VIII, SL 120).

It asks the students to make a list of how many uses they can think of optical fibres. Students try to write as many as possible. Students also mentioned or write any scientific rule which they would like to modification in it. They also make a list of the things which only can possible through modification.

Lesson No: 2, Activity No: 4.3: Make a kite (Goa, English VI, SL 24).

Students are instructed to make a kite with their friends. They collect the material like: colour paper, thread, glue, etc. After preparing a kite, try to fly it.

Lesson No: 6, Activity No: 3: Play the game 'Detective' (Goa, English VII, SL 95).

It asks the students to play the Detectives game. Students can play with each other. Students are also instructed to ask given questions and try to get their answers. They should take care during asking the questions. They should ask in polite and inoffensive manner. They cannot force the person to answer them. Students can also allow person to ask the same question to them.

Lesson No: 1, Activity No: 4.1: Discuss in group whether wars are good way to end conflict between countries. (Goa, English VIII, SL 18). 
Towards Excellence: An Indexed, Refereed \& Peer Reviewed Journal of Higher Education /

Prof.Dr. Jagdish Joshi \& Dr. Jaydip Savaliya / Page 88-109

Students are instructed to work in group and discuss whether wars are a good way to end the conflict between countries. Students present their arguments.

\section{- Making children sensitive to the environment}

Lesson No: 2, Activity No: 5: The Rainbow (Gujarat, English VI: First sem., SL 23).

This is a poem about rain and rainbow so it is includes here. Students have to read it.

There is no any activity about environment in the textbook of Standard seven.

Lesson No: 4, Activity No: 4: Solar energy (Gujarat, English VIII: First sem., SL 32).

This activity is about the Solar Energy. Information is given about Sun and Solar energy. How it produce and how to use solar energy is also described in this activity. How many ways it useful to the human being is also said in this activity.

Lesson No: 1, Activity No: 1A: Recite after teacher (Gujarat, English VIII: second sem., SL 1).

It asks the students to recite after teacher. This is a poem about one child want to become. Here gives the importance to the natural things and child want to become a tree, fish and mountain.

Lesson No: 1, Activity No: L: The unique sacrifice (Rajasthan, English VII, SL 1).

This lesson is about how Khejarli's people save trees from the royal people. They sacrifice their lives for save the trees.

Lesson No: 4, Activity No: L: Reduce waste (Rajasthan, English VII, SL 20).

It gives the information to students about how to manage wastage. This lesson is very helpful for the students in day to day life. It gives the information about- what are the preferred options for managing waste, where are people dispose kitchen waste, how are plastic bag dangerous to animal etc.

Lesson No: 15, Activity No: L: Water for all (Rajasthan, English VIII, SL 95).

This lesson is about the water and its importance. This lesson threw the light on - shortage of water and how to solve it?, where do we dumb our waste?, cause of water pollution etc.

Lesson No: 1, Activity No: L: Tree (M.P., English VI, SL 1).

Students are instructed to read the lesson about tree. This lesson about the banyan tree.

There is not even a single activity on peace in standard seven.

Lesson No: 2, Activity No: L: Thrills of Kanha Kisli (M.P., English VIII, SL 6).

Students are instructed to study this lesson. It is about Kanha Kisli nation Park. It has been protecting for its flora and fauna. It preserves the wildlife species in abundance. It is known as one of the finest and best administered National Parks in Asia.

Lesson No: 4, Activity No: 4.2: Molai's Kathoni (Maharashtra, English VI, SL 83).

This is an activity which tells a story about one great person. The name of that person is Molai. He did hard work for grow up the trees. He was devoted to his work, to grow the trees. This is really interesting and inspirable activity.

There is not even a single activity under this section in standard seven.

Lesson No: 1, Activity No: 9: Read carefully (Maharashtra, English VIII, SL 20). 
Students are instructed to read the story carefully. This is about the 'End of the World'. The fact about the Sun and scientific calculation of its hit are given in the said activity. How it destroy the earth is explained to the students by their teacher in the class.

Lesson No: 4, Activity No: P: Beauty (Goa, English VI, SL 46).

This poem is about the beauty of nature. Poet mentions where seen the beauty, where heard the beauty etc.

Lesson No: 5, Activity No: P: Tree (Goa, English VII, SL 83).

It asks the students to read the poem 'Tree'. This is about how, when and where trees use. Lesson No: 8, Activity No: L: A short monsoon diary (Goa, English VIII, SL 103).

It asks the students to study this activity carefully. This activity is about monsoon. It gives information about when does the monsoon season begins and end?, describe hill station, basic information about rain, etc.

\section{- Peace}

There is not even a single activity on peace in the textbooks of Gujarat, Rajasthan, Madhya Pradesh, Maharashtra and Goa.

\section{- Strengthen our cultural heritage and national identity}

Lesson No: 1, Activity No: 4A: Read the story (Gujarat, English VI: Second sem., SL 6).

Students are instructed to read the story. It is about the great Pandavas.

Lesson No: 4, Activity No: 7: Read and arrange (Gujarat, English VII: Second sem., SL 46).

It asks the students to read the given activity. It is about Navratri, one of the famous festival of Gujarat.

Lesson No: 3, Activity No: 4: Listen and read the story (Gujarat, English VIII: First sem., SL 15).

Students are instructed to listen and read the story. This story is about the great king Akbar and his one of the gem Tansen and his guru Sant Haridas.

Lesson No: 9, Activity No: L: Learn about the folk dance (Rajasthan, English VI, SL 64).

Students are instructed to learn about the folk dance of Rajasthan. There are different types of folk dance like: Kalbelia dance, Chari dance, Bhavai dance, Gair dance etc.

Lesson No: 11, Activity No: L: A letter from friend (Rajasthan, English VII, SL 57).

It asks the students to study this lesson carefully. This lesson is about the Hadoti region. The name come from Hadi rani. The story of Hadi rani is given here. Hadi Rani sacrificed her life for her mother land. Some popular fair of this region are also describe in the lessons. The history of this region is also given.

Lesson No: 1, Activity No: P: Chittor (Rajasthan, English VIII, SL 1).

It asks the students to study this poem carefully. This poem is about the delineation of the age old immortal glory of Chittorgarh, where the Rajput warriors fought against the Moghuls; the illegal trespassers who ventured to usurp the territory of Chittorgarh and sacrificed their lives for the sake of their holy motherland.

Lesson No: 6, Activity No: L: The test (M.P., English VI, SL 28).

This lesson is from the great history of India. It is about Pandav and Kaurav. 
Lesson No: 11, Activity No: P: Lohri (M.P., English VII, SL 80).

This is a poem on one of the Indian festival Lohri. Poet describe how it celebrated.

Lesson No: 12, Activity No: L: Know more about Bhil (M.P., English VIII, SL 102).

This lesson is about Bhil community and described their village, dresses, Dance, their ornaments, festival, routine life etc.

Lesson No: 4, Activity No: 4.6.6: Collect the stories about lives of saints that lived in Maharashtra. (Maharashtra, English VI, SL 103).

It asks the students to take the help of their teacher and collect the stories on the lives of saints who lived in Maharashtra and also collect their messages.

There is not even a single activity under this section in standard seven.

Lesson No: 1, Activity No: 12: Read and tell (Maharashtra, English VIII, SL 32).

This activity shows the grand and glorious past of India and how Indian are ahead from the world. This activity is about the medicine. This is a story about Jeevaka. Since ancient times, Indians, studied about the human body and its functioning. Before 3000 year, discussed various diseases and ailments, their symptoms, diagnosis and its cure. Here also mentioned the great book 'Ayurveda' and its features.

Lesson No: 4, Activity No: L: An Indian - American Woman in Space: Kalpana Chawla (Goa, English VI, SL 38).

This lesson is about the Kalpana Chawla. She was an astronaut. This lesson gives the information about her like: her basic information, how did she become an astronaut?, what abilities must an astronaut have, described her first mission, etc.

There is not even a single activity under this section in standard seven.

Lesson No: 3, Activity No: L: Glimpses of the past (Goa, English VIII, SL 32).

It asks the students to read it carefully. This lesson glimpses us about the past of India. This lesson covered the points like; the martyrs, the company's conquests, British rule, Ram Mohan Roy, oppression, dissatisfaction etc.

\section{- Child centred education}

Lesson No: 1, Activity No: 2: See the picture and give the answer (Gujarat, English VI: First sem., SL 2).

It asks the students to see the picture and give the answer of the questions.

Lesson

Lesson No: 3, Activity No: 5: Give the reply on the bases of sentences (Gujarat, English VII: First sem., SL 29).

It asks the students to work in pair. Write P for 'propose', A for 'Accept' and D for 'Decline' based on sentences.

Lesson No: 2, Activity No: 3: Complete the sentence (Gujarat, English VIII: First sem., SL 14).

Students are instructed to look at the pictures. They complete the sentences using the correct words.

Lesson No: 12, Activity No: 4: Tell the class about visit to a historical place (Rajasthan, English VI, SL 90).

It asks the students to tell the class about their visit to a historical place. 
Lesson No: 3, Activity No: 1.2: Complete the sentences (Rajasthan, English VII, SL 74). Students are instructed to complete the sentences. These sentences are from the poem. Lesson No: 1, Activity No: 24: A visit to the Fort of Chittorgarh (Rajasthan, English VIII, SL 5).

It asks the students to visit the fort of Chittorgarh and higher guide. Guide gives information about the fort and get some information by personal observation. Students are instructed to write about a visit of the fort of Chittorgarh.

Lesson No: 10, Activity No: 6: Collect the pictures (M.P., English VI, SL 64).

Students are instructed to collect the pictures of ten freedom fighters and past them in the notebook.

Lesson No: 14, Activity No: 6A: Write a letter (M.P., English VII, SL 106).

Students are instructed to write a letter to their friends. The content of the letter is about visit to Kanha.

Lesson No: 10, Activity No: 5: Write about the shapes and colours of balloons (M.P., English VIII, SL 83).

It asks the students to write about the different shape and colour of balloons and also mention that which other things are sold by the balloon man.

Lesson No: 1, Activity No: 1.2.1: Discuss the following questions and try to answer (Maharashtra, English VI, SL 2).

It asks the students to discuss the questions. Each question have four conditions. Students discuss it and try to give answer in English.

Lesson No: 2, Activity No: 3.2: Prepare a short note on Dead Sea and Timbuktu (Maharashtra, English VII, SL 51).

Students are instructed to prepare a short note on the said topics. Students prepare short note.

Lesson No: 3, Activity No: 1B: Discuss why poets are called 'world-losers' and 'worldforsakers' (Maharashtra, English VIII, SL 97).

It asks the students to discuss the given topic. The topic is why poets are called 'worldlosers' and 'world-forsakers'.

Lesson No: 9, Activity No: 4: Write a paragraphs on desert (Goa, English VI, SL 101).

Students are instructed to write a few paragraphs on what they see and hear in desert. Students can write it as per their imagination.

Lesson No: 6, Activity No: 5.5: Create a dialogue (Goa, English VII, SL 98).

Students are asked that is there any talking fan in their class. Students develop a dialogue between fan and mechanic.

Lesson No: 10, Activity No: 3: Imagine, you are the poet. Narrate the incident of your first meeting with Earnest (Goa, English VIII, SL 127).

It asks the students to imagine that they are poet. They come to their native place for meet the famous preacher Earnest. Students also ask to narrate their first meeting with him.

Lesson No: 9, Activity No: 4.2: Imagine you are Gathergold. Write briefly (English VIII, SL 119). 


\section{- Active and creative capabilities}

Lesson No: 4, Activity No: 4: Read the dialogue and prepare the watch (Gujarat, English Vl: First sem., SL 38).

It asks the students to read the dialogue and prepares a watch as per the instruction. Lesson No: 1, Activity No: 5: Discuss in pairs and write your point of view (Gujarat, English VII: First sem., SL 6).

It asks the students to discuss in pair and write down which other things are seen by Tejasvini from the sky.

Lesson No: 41, Activity No: 1: Take interview of your friend and write it. (Gujarat, English VIII: First sem., SL 2).

It asks the students to work in pair and take interview of his friend and write it.

Lesson No: 3, Activity No: 4: Look at the picture and describe it (Rajasthan, English VI, SL 22).

Students are instructed to look at the picture and describe it to their friend. Students can use the given clues.

Lesson No: 3, Activity No: 3.3B: Write five sentences about best friends (Rajasthan, English VII, SL 19).

Students are instructed to write five sentences about their best friends.

Lesson No: 2, Activity No: 5: Write a diary about visit to a zoo and express the feelings. (Rajasthan, English VIII, SL 13).

It asks the students to write about visit to the zoo. Students enjoyed watching the animals in the zoo. Students ask to write a diary about the visit to a zoo and express their felling.

Lesson No: 6, Activity No: 6: Write five sentences about Arjun (M.P., English VI, SL 35). It asks the students to write five sentences about Arjun. Students can take help of the given clues.

Lesson No: 6, Activity No: 6A: Write five sentences about cats (M.P., English VII, SL 46). Students are instructed to write five sentences about cats.

Lesson No: 2, Activity No: 7: Write a letter (M.P., English VIII, SL 13).

Students are instructed to write a letter to their friends and inform them about their visit to Kanha kisli. Format of the letter is given so students can use it and write a letter.

Lesson No: 2, Activity No: 2.2.8: Use imagination to complete the sentences (Maharashtra, English VI, SL 32).

Students are instructed to use their imagination to complete these sentences. Each sentence gives some condition. Students read it and give the answer according to the situations.

Lesson No: 3, Activity No: 2.3B: Frame sentences (Maharashtra, English VII, SL 90). It asks the students to prepare sentences in such a way so that the given word comes at the end.

Lesson No: 2, Activity No: 6C: Write the story (Maharashtra, English VIII, SL 66).

Students are instructed to read the story 'Don Quixote' carefully and then write the story in short.

Lesson No: 2, Activity No: 3: Work in group. Try to tell the story in English (Goa, English VI, SL 20). 
Students are instructed to work in group. Students try to tell the story in English. The points of the story are given. One person of each group can speak alternately. Teacher can also help the students. One students also write it on the board.

Lesson No: 5, Activity No: 4: Write a story (Goa, English VII, SL 82).

Students are instructed to write a story. Students prepare it based on the mentioned points. Lesson No: 2, Activity No: 4: Write a diary entry of their experience about Tsunami (Goa, English VIII, SL 28).

It tells the students, imagine that they go to Andaman and Nicobar Islands as a volunteers for relief work after the Tsunami. Students heard many incident about the bravery deed of ordinary people. Students should write these incidents as a diary.

\section{- Children find their voices and nurture their curiosity}

Lesson No: 4, Activity No: 10: Explain which things are forgotten by students and their family members (Gujarat, English Vl: First sem., SL 45).

This activity is about, normally which things are forgotten by different members of family to take with them when they go out from home. Write and explain it in front of class.

Lesson No: 1, Activity No: 12: Imagine a device like flying bicycle, drew its picture (Gujarat, English VII: Second sem., SL 13).

It asks the students about their thoughts to prepare a new device like flying bicycle. Students draw the picture of that device. Write parts name in English. Students also mention that which scientific rules use in it.

Lesson No: 1, Activity No: 5: What questions would they ask? (Gujarat, English VIII: First sem. SL 10).

Teacher asks to the students if they met Kanaiyalal Munshi when he was a governor of UP, Which questions would students ask him. Each student has to mention six questions which he would like to ask him.

Lesson No: 6, Activity No: 3: Write a letter (Rajasthan, English VI, SL 46).

It asks the students to write a letter to their friend. The content of the letter is based on Maharana Pratap. Some clues are given. Students use it and write a teller to their friends. Lesson No: 6, Activity No: 5: How Sheru need to be examined (Rajasthan, English VII, SL 36).

It asks the students to write a paragraph on how Sheru need to be examined. Students have to write on the basis of given points.

Lesson No: 8, Activity No: 5: Write a brief life sketch of any national or regional hero/heroin (Rajasthan, English VIII, SL 53).

It asks the students to write a detail life sketch of any national or regional hero/heroin from the history of Rajasthan.

Lesson No: 5, Activity No: 2.2: Compare the poem (M.P., English VI, SL 26).

It asks the students to read the poem given in this activity. They compare this poem with the poem which they read. Students have to declare that which poem they like most. They also give the reason why they like the particular poem.

Lesson No: 2, Activity No: 6A: Write a paragraph (M.P., English VII, SL 10).

It asks to the students to write a paragraph. Students use given group of words and complete the paragraph. 
Lesson No: 8, Activity No: 5: Write a dialogue (M.P., English VIII, SL 72).

It asks the students to write a dialogue between the earth and the moon. Some clues are given. It is helpful to the student to write a dialogue.

Lesson No: 1, Activity No: 1.6.6: Try to make as many meaningful sentences as he can (Maharashtra, English VI, SL 22).

It asks the students to use the words in the neighbouring boxes, try to make as many meaningful sentences as students can do. Students also provide one example for this activity so they can do it properly.

Lesson No: 3, Activity No: 11.3: Rewrite any one story out of three stories in the form of playlet. (Maharashtra, English VII, SL 116).

It asks the students to prepare playlet form from the three stories and rewrite it. Students also write stage direction and then enact their play.

Lesson No: 1, Activity No: 8D: Retell the story (Maharashtra, English VIII, SL 19).

It asks to the students to read the story 'Abou Ben Adhem'. After reading the story, students are instructed to retell the story in their own words.

Lesson No: 1, Activity No: 3: Say what you feel about homework (Goa, English VI, SL 10). It asks the students to express their thought or what they feel about homework. Students work in par and speak to each other, do they think it is useful, even though they may not like it.

Lesson No: 7, Activity No: 4.2: Write a paragraph. (Goa, English VII, SL 106).

Students are instructed to see given example and find out something interesting about age or growing old. Students write about it.

Lesson No: 7, Activity No: 4.3: Write a notice (Goa, English VIII, SL 97).

Students are instructed to write a notice for the school notice board. Four steps of notice writing are given.

\section{- Children learn in variety of ways.}

Lesson No: 1, Activity No: 8: Listen and read the story (Gujarat, English VI: First sem., SL 10)..

Students are instructed to listen when the teacher reads the story. After that, read the story and friends listen it.

Lesson No: 1, Activity No: 5: Teacher tell the story, listen carefully and do the silent reading (Gujarat, English VII: First sem., SL 5).

Students are instructed to listen the story. Teacher tells the story then they do the silent reading.

Lesson No: 2, Activity No: 2: See the picture and study the information (Gujarat, English VIII: First sem. SL 13).

Students are instructed to see the picture and study the information. This picture is of Burj Khalifa the tallest building of the world and gives the information about it.

Lesson No: 1, Activity No: L: Read the conversation (Rajasthan, English VI, SL 1).

Students are instructed to read the conversation. It is about Health and Hygiene. This is in a dialogue form between teacher and students.

Lesson No: 14, Activity No: 3: Look at the picture (Rajasthan, English VII, SL 80).

It asks the students to look at the pictures. These pictures are described prepositions. 
Lesson No: 13, Activity No: 3: Teacher recite and student follow (Rajasthan, English VIII, SL 86).

Students are instructed to recite the lines after teacher.

Lesson No: 6, Activity No: 5.1: Let's read (M.P., English VI, SL 35).

Students are instructed to read the story and give the answers of the given questions.

Lesson No: 2, Activity No: 4: Join the pair of sentences (M.P., English VII, SL 9).

It asks the students to join the pair of sentences using 'Who'.

Lesson No: 13, Activity No: 4: Let's learn (M.P., English VIII, SL 119).

Students are instructed to study, read and comprehend given material

Lesson No: 2, Activity No: 2.7: What the ad says (Maharashtra, English VI, SL 50).

It asks the students to read the ads and comprehend its juice what they want to convey.

Lesson No: 1, Activity No: 9: Listen, read aloud and sing (Maharashtra, English VII, SL 22).

Students are instructed to listen, read aloud and sing the poem.

Lesson No: 1, Activity No: 10: Listen, read and discuss (Maharashtra, English VIII, SL 27).

Students are instructed to listen, read and discuss the story 'Beware of Superstition'.

Lesson No: 7, Activity No: 2: Replace the italicised portion of each sentence below with suitable phrase from the box (Goa, English VI, SL 80).

Students are instructed to replace the italicise part from the sentences and put the proper phrases from the box. Students also take care of other necessary changes.

Lesson No: 2, Activity No: 3: Read the following sentences (Goa, English VII, SL 30).

It asks the students to read given sentences. It is about if-clause.

Lesson No: 9, Activity No: 3.3: Complete the sentences (Goa, English VIII, SL 118).

Students are instructed to complete the sentences with the appropriate forms of the verbs in bracket.

\section{- Learn through direct experience}

Lesson No: 4, Activity No: 5: Note down the time of different watch (Gujarat, English VI: First sem., SL 40).

Teacher prepares six clock and gives it to six different students. They stand in different places of classroom. Students go there and note the time of the watch.

Lesson No: 3, Activity No: 8: Project (Gujarat, English VII: First sem., SL 33).

Students are instructed to collect the rappers and on the bases of it complete the table. Student have to write a things like: product name and ingredients. Students take the help of the science teacher to decide the ingredients are harmful or harmless.

Lesson No: 2, Activity No: 2B: Prepare a rhyme (Gujarat, English VIII: Second sem. SL 13).

It asks the students to make similar type of rhyme by replacing the objects and colours given in the rhyme. Students use the clues given in the table. The table have two columns like: Objects and Colours. Students are used this objects and colours and prepare a similar rhymes.

Lesson No: 2, Activity No: 1B: Prepare a rhyme (Rajasthan, English VI: Second sem. SL 14).

It asks the students work in group and read the information which is given in the table. Prepare a rhyme on the bases of it. 
Lesson No: 4, Activity No: 4: Visit public place (Rajasthan, English VII, SL 24).

It asks the students to visit public place like school/ bus stand, etc. Students ask the question they are dirty or not. If they are dirty then find out the reasons and speak in the class. Students also give advice or discuss what they can do to keep the public places clean.

There is no any activity under this topic in the textbook of standard eight.

Lesson No: 6, Activity No: 5: Ask the friends and complete the table (M.P., English VI, SL 34).

It asks the students to communicate with their friends. They ask them which games they like or not and complete the given table. There are three columns- name of game, I like, I don't like. There are eight games.

Lesson No: 5, Activity No: 7B: Fill up railway reservation forms (M.P., English VII, SL 33).

It asks the students to get a railway reservation form from the railway reservation window and fill it.

Lesson No: 11, Activity No: 8B: Give way to the waste water of your house to your kitchen garden (M.P., English VIII, SL 101).

It asks the students to use the wastage water of house in the kitchen garden.

Lesson No: 4, Activity No: 4.4.8: Hold an exhibition (Maharashtra, English VI, SL 96).

It asks the students to hold an exhibition of different shops in the classroom.

Lesson No: 1, Activity No: 2: Write about self (Maharashtra, English VII, SL 4).

Students are instructed to write about their self. There are some points mention in the activity for write about their self. The instructions are given there. Students write as per said instruction.

Lesson No: 3, Activity No: 6F: Be a detective (Maharashtra, English VIII, SL 112).

Students are instructed to choose any three objects from their surroundings. These objects must be from home, in school, on the way to school etc. Students can choose things, persons, animals, plants etc. as an object. After selecting objects, students observe each object very carefully as well as write their observations. Students write something whatever they deduce from the observation at last.

Lesson No: 2, Activity No: 4.3: Make a kite (Goa, English VI, SL 24).

Students are instructed to make a kite with their friends. They collect the material like: colour paper, thread, glue, etc. After preparing a kite, try to fly it.

Lesson No: 5, Activity No: 3.4: Speak to five adult in your neighbourhood. Ask them questions (Goa, English VII, SL 81).

Students are instructed to communicate with the adult who live near to them. Some questions are given here, ask these questions to them. Students share their findings with the class. These questions are related with the use of plastic packet, from where to purchase?, about footwear and cloth.

There is no any activity under this point

\section{- Learners to engage with concepts and deepen understanding, variety and challenge and be interesting and engaging}


Lesson No: 4, Activity No: 9: True and false (Gujarat, English VI: First sem., SL 44). It asks the students to say whether the sentences are true or false on the bases of given incident.

Lesson No: 3, Activity No: 6C: Find out the sentences from the story (Gujarat, English VII: Second sem., SL 34).

It asks the students to find out the sentences from the story which are similar meaning of the given sentences.

Lesson No: 1, Activity No: 4: Match the column (Gujarat, English VIII: First sem. SL 9).

It asks the students to match ' $A$ ' column with ' $B$ '. There are five words in column ' $A$ ' and its meaning is given in the column in ' $B$ '. Students match the words with its meaning.

Lesson No: 5, Activity No: 5A: Tick the correct alternative (Rajasthan, English VI, SL 35).

It asks the students to tick the correct alternative. There are two MCQ type questions. Students select the right option from it.

Lesson No: 3, Activity No: 2.2: Rearrange the letters to form meaningful words (Rajasthan, English VII, SL 18).

It asks the students to rearrange the letters in such a way so that make a meaningful words out of it. There are six words. Each word rearranges and makes proper spelling.

Lesson No: 1, Activity No: 2: Match the words (Rajasthan, English VIII, SL 1).

It informs the students that there are two columns. There are five words in column ' $A$ ' and students find out the rhyming words of them from column ' $\mathrm{B}$ '.

Lesson No: 1, Activity No: 1.1: Make a new words (M.P., English VI, SL 3).

It asks the students to make a new words by joining words which are given in the table.

Lesson No: 4, Activity No: 2: Answer the questions (M.P., English VII, SL 21).

It asks the students to give answer of the questions.

Lesson No: 2, Activity No: 6: Complete the given information (M.P., English VIII, SL 12).

It asks the students to read given material and then complete the information.

Lesson No: 1, Activity No: 1.2.9: Read the situation and the answer (Maharashtra, English VI, SL 6).

It asks the students to read different situations which are mentioned in the activity and answer them. Students guess 'Why' Akshay asks that question.

Lesson No: 2, Activity No: 5.1: Put the events in the right order (Maharashtra, English VII, SL 57).

It asks the students to arrange the events in the right order. They write down about each event.

Lesson No: 1, Activity No: 1B: Answer the questions (Maharashtra, English VIII, SL 2). It asks the students to give answer the questions.

Lesson No: 1, Activity No: 1: Answer the following questions (Goa, English VI, SL 8).

It asks the students to give answer. There are six questions and all are from the lesson.

Lesson No: 4, Activity No: 1: Answer the following questions (Goa, English VII, SL 63).

It asks the students to give the answer of these questions. These questions are based on lesson.

Lesson No: 4, Activity No: 3.1: Fill in the blanks (Goa, English VIII, SL 64).

Students are instructed to read the given material and fill the blanks. 


\section{- Team work}

Lesson No: 1, Activity No: 6: Work in group (Gujarat, English VI: First sem., SL 8)..

Students are instructed to work in group. Do the question answer with the friends and complete the given table and present it in front of class.

Lesson No: 2, Activity No: 6: Work in group and complete the dialogue (Gujarat, English VII: First sem., SL 20).

It asks the students to work in group and complete the dialogues and enact it in the class. Lesson No: 1, Activity No: 3: Solve riddles in group (Gujarat, English VIII: First sem. SL 4). Students are instructed to try to solve riddles in groups then write the answer.

Lesson No: 3, Activity No: 2B: Work in pair (Rajasthan, English VI, SL 21).

Lesson No: 8, Activity No: 5.1: Discuss and write why conservation efforts need to be encouraged (Rajasthan, English VII, SL 46).

Students are instructed to work in group, discuss and write why conservation effort need to be encouraged. Students present their point of views for what can students do to aid conservation effort.

Lesson No: 14, Activity No: 4: Speak few sentences about the places which they have visited (Rajasthan, English VIII, SL 94).

Students are instructed to work in the group. The class divide in two groups and ask them to speak few sentences about the places they have visited.

Lesson No: 4, Activity No: 4: Discuss in pair and find the answers (M.P., English VI, SL 19).

Students are instructed to work in pair, discuss the given questions in pair and find the answers.

Lesson No: 9, Activity No: 5: Work in pair and answer the questions (M.P., English VII, SL $69)$.

Students are instructed to work in pair and answer the questions. These questions are based on lesson.

Lesson No: 3, Activity No: 5: Talk about the Nobel Prize (M.P., English VIII, SL 20).

Students are instructed to work in pair and talk about the Noble Prize. There are some clues.

Lesson No: 1, Activity No: 1.2.4: Work in pair. Any number of thinking (Maharashtra, English VI, SL 4).

Students are instructed to form pairs or groups. One person says any number from one to ten thousand. Other suggest names, suitable objects or things for the number.

Lesson No: 2, Activity No: 4: Form group of four to six. Discuss each of the given topic (Maharashtra, English VII, SL 53).

Students are instructed to work in group and discuss each given topics. Students can take help of their mother tongue for this activity. Each person from the group should choose a topic and speaks about it for one minute in English. Topics are - 'What may happen', 'What will never happen' etc. 
Lesson No: 4, Activity No: 13B: Form group and write a conversation (Maharashtra, English VIII, SL 74).

It asks the students work in group of four to six. Students do this activity as a group activity and write a conversation in which person / a group of persons thank someone.

Lesson No: 2, Activity No: 3: Work in group. Try to tell the story in English (Goa, English $\mathrm{VI}, \mathrm{SL} 20)$.

Students are instructed to work in group. Students try to tell the story in English. The points of the story are given. One person of each group can speak alternately. Teacher helps the students. One students also write it on the board.

Lesson No: 9, Activity No: 3.4: Work in group. (Goa, English VII, SL 138).

Students are instructed to work in group, discuss and guess, a snake has no legs even though it moves very fast.

Lesson No: 4, Activity No: 3.4: Work in group and rearrange the words (Goa, English VIII, SL 65).

It asks the students to work in group, rearrange the words and make a correct and meaningful sentence.

\section{- Attainment of a basic proficiency and development of language}

Lesson No: 1, Activity No: 3A: Listen and read the dialogue (Gujarat, English VI: First sem., SL 3).

It asks the students to listen and read the dialogue.

Lesson No: 1, Activity No: 7: Answer the question (Gujarat, English VII: First sem., SL 7).

It asks the students to answer the question. There are four descriptive type question. Students have to write in detail.

Lesson No: 1, Activity No: 4: Listen and read the play (Gujarat, English VIII: First sem. SL 5).

It asks the students to listen and read the given play.

Lesson No: 1, Activity No: 3: Read the given sentences (Rajasthan, English VI, SL 6).

It asks the students to read the given sentences. Students have to pay attention on the use of 'A', 'An' and 'The'.

Lesson No: 7, Activity No: 3: Read the poem (Rajasthan, English VII, SL 39).

The whole class is divide in the two groups and read the poem about a careless boy.

Lesson No: 3, Activity No: 4: Tell about Pannadhai's sacrifice (Rajasthan, English VIII: Second sem. SL 20).

Students are instructed to tell the story which they heard about Pannadhai's sacrifice and also explain how she saved the prince.

Lesson No: 12, Activity No: 5: Write a story (M.P., English VI, SL 75).

It asks the students to listen and repeat the words. There are some words through which students get the practice of listening and speaking of these words.

Lesson No: 7, Activity No: 1: Read and learn (M.P., English VII, SL 49).

Students are instructed read the given phrases and learn it.

Lesson No: 7, Activity No: 4A: Read the sentences (M.P., English VIII, SL 60). 
It asks the students to read the sentences. These sentences are explain the use of some conjunction.

Lesson No: 1, Activity No: 1.1.3: The Wild boar and the fox (Maharashtra, English VI, SL 7).

It asks the students to read the given story.

Lesson No: 1, Activity No: 1: Listen and read aloud (Maharashtra, English VII, SL 1).

Students are instructed to listen and read the poem.

Lesson No: 3, Activity No: 9F: Use imagination and write (Maharashtra, English VIII, SL 120).

It asks the students to make a list of how many uses they can think of optical fibres. Students try to write as many as possible. Students write any scientific rule which they would like modification in it. They also make a list of things which only can possible through modification.

Lesson No: 7, Activity No: L: Fair play (Goa, English VI, SL 82).

It asks the students to read the lesson 'Fair play'.

Lesson No: 9, Activity No: 2.1: Read the following sentences (Goa, English VII, SL 133).

Students are instructed to read given sentences. These sentences or materials are about Modal Auxiliaries.

Lesson No: 8, Activity No: L: A short monsoon diary (Goa, English VIII, SL 103).

It asks the students to read it carefully.

\section{- Designers of textbooks provide guidance to teacher regarding ways in which the subject matter can explored}

Lesson No: 2, Activity No: 2: Play the game (Gujarat, English VI: First sem., SL 29).

Guidance is given to the teacher about how to articulate this activity properly in the classroom.

Lesson No: 3, Activity No: 4: Play the Game (Gujarat, English VII: Second sem., SL 34).

Here help line is given for the teacher. Helpline is about which types of response and circumstances teacher can use?

Lesson No: 1, Activity No: 9: Plan for the modernising the village after flood (Gujarat, English VIII: Second sem. SL 12).

Students are instructed to work in group and prepare a plan for the modernising the village after flood. The helpline is given for the teacher so he can give proper guidance for the said activity. How to work / develop the present project is mention in helpline.

There is not even a signal time given any help line or instruction in the textbook of standard six, seven and eight of Rajasthan, Madhya Pradesh, Maharashtra and Goa

\section{- Performing a small drama or enact a dialogue}

Lesson No: 4, Activity No: 2: Listen, read and enact the story (Gujarat, English VI: First sem., SL 37). 
Students are instructed to listen, read and then enact the given story. This story is about the tower clock.

Lesson No: 1, Activity No: 3D: Read the dialogue and enact (Gujarat, English VII: Second sem., SL 3).

Students are instructed to read the dialogue silently and then enact it.

Lesson No: 1, Activity No: 7B: Study dialogue and enact (Gujarat, English VIII: Second sem. SL 11).

Students are instructed to work in pairs. Students study dialogues and enact it with their friend.

There is no any activity under this section in the textbook of standard six, seven and eight of Rajasthan and Goa.

There is no any activity under this section in standard six.

Lesson No: 5, Activity No: 7A: Role play (M.P., English VII, SL 33).

Students are instructed to work in pairs and present role play. Students read the telephonic conversation and enact the role play in the class.

Lesson No: 6, Activity No: 6: Read and enact the story (M.P., English VIII, SL 53).

Students are instructed to read the story "Measure for Measure" and then enact it.

Lesson No: 2, Activity No: 2.2.6: Enact the skit (Maharashtra, English VI, SL 36).

Students are instructed to enact the skit which is given in the activity.

Lesson No: 1, Activity No: 3: Form groups of four to eight and enact the conversation which they have written on the bases of picture. (Maharashtra, English VII, SL 5).

Students are instructed to work in group of four to eight and enact the conversation which they have written on the bases of picture.

Lesson No: 2, Activity No: 4: Read carefully and enact (Maharashtra, English VIII, SL 54).

Students are instructed to read the story, explaining it and enact.

\section{Comparison}

Table 1

Percentage of following NCF 2005

\begin{tabular}{|l|l|l|l|l|l|}
\hline NCF & Gujarat & Rajasthan & Madhya Prades & Maharashtra & Goa \\
followed \\
by each \\
state
\end{tabular}


Towards Excellence: An Indexed, Refereed \& Peer Reviewed Journal of Higher Education /

Prof.Dr. Jagdish Joshi \& Dr. Jaydip Savaliya / Page 88-109

\section{Series 1}

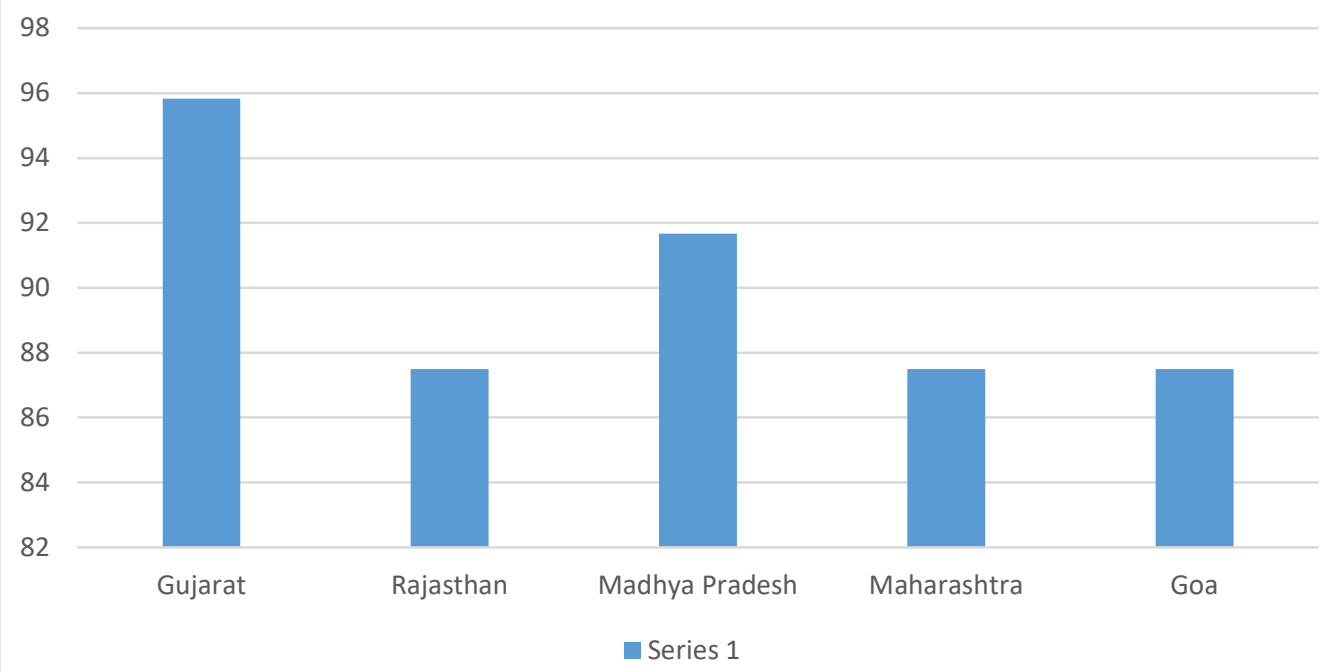

Fig. 1. Percentage of following NCF 2005

Analysis of the English textbooks of standard six, seven and eight of all five states are showed that Gujarat is on the first place. The percentage of Gujarat is 95.83. Madhya Pradesh is on the second place. The percentage of Madhya Pradesh is 91.67. Rajasthan, Maharashtra and Goa are on the last place with the $87.50 \%$. This is the state wise percentage of NCF. All the states are followed NCF above $87 \%$. It is a good score.

\section{Conclusion}

It is believed that the textbook is a significant medium in the present education system. Textbook is one of the proven authoritative sources to establish values in students in the elementary stage. Students are mostly depended on the textbook at this stage. So it is necessary, the textbook should be a complete package which develops students' life in all strata of life. NCERT develops National Curriculum Framework which provides guidelines for developing textbooks and school curriculum. NCF-2005 prepared by NCERT discusses an extensive assortment of issues regarding school education. So evaluate the textbooks of English of standard six, seven and eight of regional medium of western region of India in the light of NCF 2005. Textbooks of English are assessed with the reference of NCF2005. Above mentioned parameters are used to evaluate the English textbooks of upper primary schools. English textbooks have almost all the qualities or as per the NCF-2005's suggestion except one parameters. Out of all the textbooks of five states there is no any activity which is based on "Peace'. Researcher found that said textbooks are decent and team of textbook preparation work properly to follow NCF. All the states are followed NCF above $87 \%$. It is a good score. 


\section{Works Cited}

Behera,Arun K. "ELT in India: An Analysis." International Journal on Studies in English Language and Literature.1.1 (2013): 1-5. Web. 28 Feb. 2017.

Bhosala, Akhil., et al. My English Book six: Standard Six. Mumbai: Maharashtra state Textbook Bureau, 2016. Print.

Gupta, Purushottam., et al. English Reader: Class- VI. Jaipur: Rajasthan State Textbook Board, 2016. Print.

Irani, Samannaz., et al. My English Book Seven: Standard Seven. Mumbai: Maharashtra state Textbook Bureau, 2016. Print.

---. et al. My English Book Eight: Standard Eight. Mumbai: Maharashtra state Textbook Bureau, 2016. Print.

Jain, Neeta., et al. English Reader (General Series).: Class - 6. Bhopal: M.P. Textbook Corporation, 2016. Print.

---. et al. English Reader (General Series).: Class - 7. Bhopal: M.P. Textbook Corporation, 2016. Print.

Jat, Madhav Lal., et al. English Reader: Class- VIII. Jaipur: Rajasthan State Textbook Board, 2016. Print.

Kanwar, Saroj., et al. English Reader: Class- VII. Jaipur: Rajasthan State Textbook Board, 2016. Print.

M. Vijayalakshmi and ManchiSaratBabu. "A brief History of English Language Teaching in India." International Journal of Scientific and Research Publications. 4.5 (2014): 1-5. Web. 28 Feb. 2017.

Malini, S. Devika. "English Language Teaching in India- A Critical Evaluations of ELT in India." International Multidisciplinary Research Journal. 1.7 (2011): 52-54. Web. 28 Feb. 2017.

Modern Language Association. MLA Handbook for Writers of Research Papers. 8th ed. New Delhi: East-West Press Pvt Ltd., 2009. Print.

"National Curriculum Framework." Wikipedia: The Free Encyclopedia. en.wikipedia.org. N.p., Web. 28 Feb. 2017.

Pal, Yesh. National Curriculum Framework 2005. New Delhi: NCERT, N.d. Print.

Pallath, Pratheesh. "History of Development of Curriculum Framework." pratheeshpallath.blogspot.in.N.p., Oct. 2016. Web. 28 Feb. 2017.

Parab, Vitthal. "A Critical Analysis of the Contemporary Status of English Language Teaching in India."International Journal of Applied Research. 1.9 (2015): 1-3. Web. 28 Feb. 2017.

Patel, Rakesh., et al. English Standard six: First Semester. Gandhinagar: Gujarat state School Textbook Board, 2016. Print.

---. et al. English Standard six: Second Semester. Gandhinagar: Gujarat state School Textbook Board, 2016. Print.

---. et al. English Standard Seven: First Semester. Gandhinagar: Gujarat state School Textbook Board, 2016. Print. 
---. et al. English Standard Seven: Second Semester. Gandhinagar: Gujarat state School Textbook Board, 2016. Print.

---. et al. English Standard Eight: First Semester. Gandhinagar: Gujarat state School Textbook Board, 2016. Print.

---. et al. English Standard Eight: Second Semester. Gandhinagar: Gujarat state School Textbook Board, 2016. Print.

Pondra, Rajender. "English Language Teaching in India: A Review." Paripex- Indian Journal of Research. 5.2 (2016): 23-25. Web. 28 Feb. 2017.

Pal, Yesh. National Curriculum Framework 2005. New Delhi: NCERT, N.d. Print.

Singh, Namwar., et al. Honeysuckle: Textbook in English for Class VI. Goa: Directorate of Education, 20016. Print.

---. et al. Honeysuckle: Textbook in English for Class VII. Goa: Directorate of Education, 20016. Print.

---. et al. Honeysuckle: Textbook in English for Class VIII. Goa: Directorate of Education, 20016. Print.

Shrivastava, Preeti., et al. English Reader (General Series).: Class - 8. Bhopal: M.P. Textbook Corporation, 2016. Print.

\author{
Prof. Dr. Jagdish S Joshi \\ Professor-Director \\ UGC HRDC, Gujarat University, Ahmedabad \\ joshijagdish@yahoo.com, M. 9426587963 \\ $\&$ \\ Dr. Jaydip K. Savaliya \\ jaydipsavaliya007@gmail.com, M. 9924257443
}

